\title{
A utilização dos mapas conceituais no ensino de ciências nos anos iniciais
}

\author{
The use of conceptual maps in science teaching in initial years
}

\author{
Leonir Lorenzetti" \\ Virginia Rotters da Silva*
}

\section{Resumo}

Este trabalho analisou as contribuições do uso do mapa conceitual no processo de ensino e aprendizagem com alunos do $4^{\circ}$ ano do ensino fundamental de uma escola pública municipal de Araucária, PR. Partindo-se de uma sequência didática sobre a água, foi solicitado aos alunos que elaborassem, em grupo, um mapa conceitual que expressasse o conhecimento científico construído ao longo de seis aulas. Os mapas conceituais foram analisados a fim de verificar como o conhecimento foi representado bem como a compreensão da técnica de mapeamento. Verificou-se que o mapa conceitual se mostrou importante na representação do conhecimento dos alunos, que houve ampliação do vocabulário científico proposto no plano de aula, porém, sem profundidade nas relações entre conceitos, pois nem todos os alunos demonstraram compreensão plena daquilo que representaram. Constatou-se que os alunos tiveram dificuldade para representar o conhecimento por meio dos mapas, não porque não sabiam, mas pela inexperiência na sua construção e utilização, demonstrando assim a necessidade de um período maior de tempo para aplicação e intervenções.

Palavras-chave: Anos iniciais. Ensino de ciências. Mapas conceituais.

\section{Abstract}

The study analyzed the contributions of the use of the conceptual map in the teaching and learning process with students from the 4th year of elementary school in a municipal public school in Araucária, PR. Starting from a didactic sequence on the theme water, the students were asked to elaborate in a group a conceptual map that expresses the scientific knowledge constructed during six classes. The conceptual maps were analyzed in order to verify how the knowledge was represented, as well as the understanding of the mapping technique. It was verified that the conceptual map was important in the representation of students' knowledge, that there was an expansion of the scientific vocabulary proposed in the lesson plan, but without depth in the relations between concepts, since not all the students demonstrated a full understanding of what they represented. It was found that students had difficulty representing knowledge through maps, not because they did not know, but because of inexperience in its construction and use, thus demonstrating the need for a longer period of time for the application and interventions.

Keywords: Initial years. Science teaching. Conceptual map.

\author{
Recebido em 19/10/2017 - Aprovado em 29/01/2018 \\ http://dx.doi.org/10.5335/rep.v25i2.8170
}

Doutor em Educação Científica e Tecnológica pela Universidade Federal de Santa Catarina. Professor da Universidade Federal do Paraná, no curso de licenciatura em Química e Ciências Biológicas e no Programa de Pós-Graduação em Educação em Ciências e em Matemática. E-mail: leonirlorenzetti22@gmail.com

** Mestre em Educação em Ciências e em Matemática pela Universidade Federal do Paraná. Professora do quadro da Secretaria Municipal de Educação de Curitiba. E-mail: vicaroters@gmail.com 


\section{Introdução}

A teoria dos mapas conceituais (MC) foi desenvolvida por Joseph Novak (1998) em 1972, quando trabalhava com muitos dados de entrevistas clínicas piagetianas e necessitava de um instrumento para organizar esse material. O mapa conceitual se fundamenta na teoria da aprendizagem significativa de Ausubel (2003), o qual aponta que o ser humano organiza o seu conhecimento por meio da hierarquização de conceitos, e que os novos conhecimentos se fixam quando são relacionados com aquilo que já se conhece, ou seja, quando as ideias já existentes são modificadas a partir de novas ideias, estabelecendo conexões. Os mapas conceituais podem promover mais que uma representação esquemática ou o estabelecimento de relações entre os conceitos. Eles podem propiciar a aprendizagem significativa, contribuindo para a construção do conhecimento científico.

Mapa conceitual é considerado como um estruturador do conhecimento, na medida em que permite mostrar como o conhecimento sobre determinado assunto está organizado na estrutura cognitiva de seu autor, podendo visualizar e analisar a sua profundidade e a extensão. Ele pode ser entendido como uma representação visual utilizada para partilhar significados, pois explicita como o autor entende as relações entre os conceitos enunciados.

Os mapas conceituais não são autoexplicativos, é necessário que o autor explicite os conceitos e as relações estabelecidas entre eles. Embora possam ser usados para dar uma visão geral do tema em estudo, para fazer um bom mapa conceitual, é necessário que o seu idealizador saiba fazê-lo e que já tenha adquirido certa familiaridade sobre o assunto a ser organizado. Na sua utilização como ferramenta de ensino e avaliação da aprendizagem significativa, podem trazer uma maior clareza no entendimento do pensamento construído pelo aluno ao longo da aprendizagem de conteúdos em um determinado processo de construção de conhecimento.

De acordo com Cañas, Novak e Reiska (2015, p. 10), o mapa constitui-se em "estrutura e conteúdo". A estrutura consiste na presença de características estruturais, como níveis hierárquicos, número de proposições, quantidade de cross links, entre outros aspectos. Já o conteúdo é expresso por meio de seus conceitos, suas frases de vinculação e proposições que formam, isto é, a qualidade dos conceitos, das proposições e explicações.

Para se obter uma melhor compreensão da maneira como o conhecimento é representado por meio dos mapas conceituais, Novak e Gowin (1996) usam os seguintes critérios de análise e classificação dos mapas conceituais: proposições, hierarquia, ligações cruzadas ou transversais e exemplos, com a finalidade de analisar qualitativamente os mapas construídos, em suas características tanto estruturais (forma) quanto semânticas (conteúdo), conforme Quadro 1. 


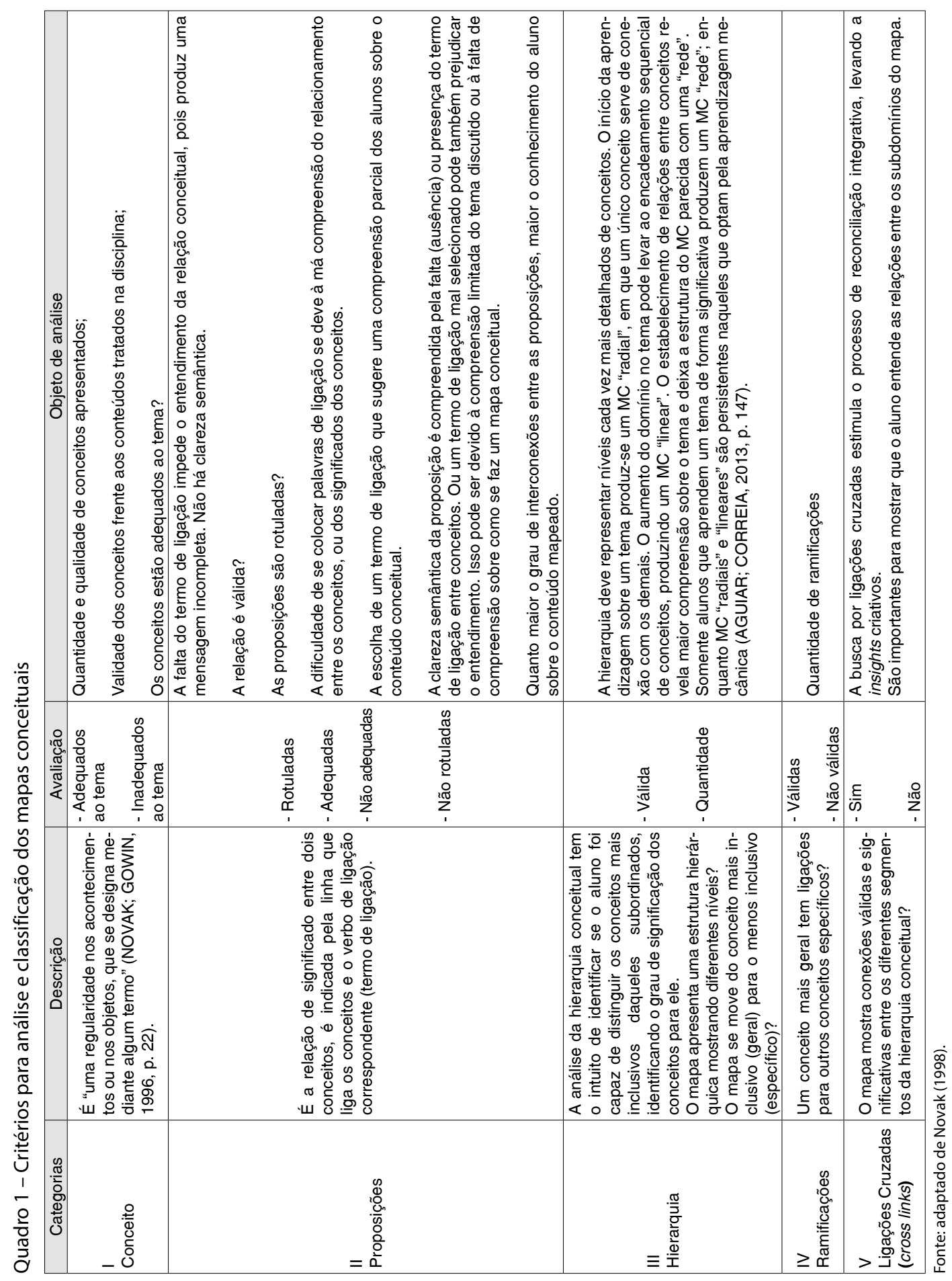


Sendo os mapas conceituais ferramentas gráficas que permitem a construção, a organização, a representação e a avaliação do conhecimento de forma diferenciada, quando devidamente utilizados e aplicados como recurso, tornam-se instrumentos potencializadores, contribuindo para a aprendizagem significativa dos alunos. A tendência desse recurso didático é ser um instrumento facilitador no processo de ensino e aprendizagem, em contraste com a didática tradicional dos professores, tornando, assim, as aulas mais aprazíveis, dinâmicas e eficientes, intensificando e reforçando a aprendizagem significativa.

Nesse sentido, o trabalho com mapas conceituais apresenta-se como uma possibilidade para professores e alunos acompanharem avanços e limitações ao longo desse processo, pois proporciona não somente a organização de um dado ou informação meramente disponível, mas em especial do conhecimento.

Sabe-se que não existe um mapa conceitual "correto" sobre um certo conteúdo. O que importa não é se o mapa está certo ou não, mas, sim, se ele dá evidências de que os alunos estão aprendendo significativamente o conteúdo, ao invés de se preocupar em atribuir um escore ao mapa.

Por ser um recurso utilizado com diversas finalidades no contexto escolar, acredita-se na importância da sua utilização como ferramenta pedagógica no processo de ensino e aprendizagem de ciências, visando contribuir para a elaboração de metodologias diferenciadas na construção do conhecimento pelos alunos.

Os mapas conceituais têm sido objeto de estudos variados, como os efetuados na Espanha, por Antônio Ontoria Peña (Escola Universitária de Magistério de Córdoba), nos Estados Unidos, por Novak, Gowin e Canãs (Florida Institute for Human and Machine Cognition), e no Brasil, por Marco Antônio Moreira, no Instituto de Física da Universidade Federal do Rio Grande do Sul (Ufrgs), por Paulo Rogério Correia, na Escola de Artes, Ciências e Humanidades da Universidade de São Paulo (Leste), por Romero Tavares, na Universidade Federal da Paraíba, e por Ítalo Dutra, do Laboratório de Estudos em Educação a Distância da Ufrgs, entre outros.

Os mapas conceituais também são discutidos e investigados em cursos de graduação, programas de pós-graduação, cursos de formação continuada e disseminados em eventos científicos na área da educação em ciências.

O estudo de Silva e Lorenzetti (2016) objetivou investigar como os mapas conceituais estão sendo utilizados no ensino de ciências. A pesquisa analisou as características e as contribuições dos mapas conceituais para a educação em ciências apresentados nas Atas do Encontro Nacional de Pesquisa em Educação em Ciências, no período de 1997 a 2015. Foram identificados vários estudos na literatura sobre estratégias de aprendizagem com mapas conceituais, sendo constatado 
que a maioria dos trabalhos apresentados eram voltados para o ensino superior (37\%), o ensino médio ( $35 \%$ ) e o ensino fundamental II (12\%), tendo como foco principal as disciplinas Física, Química e Biologia. Os autores destacam a ausência de trabalhos envolvendo os anos iniciais do ensino fundamental, evidenciando que a temática é pouco pesquisada nesse nível de ensino.

Dos 43 trabalhos analisados, 22 estavam voltados para a educação básica, sendo 1 trabalho na educação infantil $(4,5 \%), 5$ nos anos finais do ensino fundamental (23\%), 15 no ensino médio (68\%) e 1 aplicado em vários níveis (4,5\%).

Os autores identificaram que a prioridade nos trabalhos foi o coletivo dos alunos com 18 (83\%), os quais colocam o aprendizado do aluno como foco de interesse, e que os mapas conceituais foram utilizados, em sua maioria, como recurso útil para o desenvolvimento da aprendizagem significativa. Os outros quatro trabalhos deram destaque para a formação continuada dos professores e o uso dos mapas conceituais como estratégia de avaliação ou planejamento, compondo o coletivo de professores (SILVA; LORENZETTI, 2016).

Tendo em vista essa investigação e considerando que o mapa conceitual é uma estratégia potencialmente facilitadora da aprendizagem significativa, além de ser uma técnica muito flexível e que pode ser usada em diversas situações como instrumento de análise de currículo, técnica didática, recurso de aprendizagem e avaliação, propôs-se este estudo para verificar a contribuição do uso do mapa conceitual no processo de ensino e aprendizagem dos alunos dos anos iniciais do ensino fundamental, desenvolvido por meio de uma sequência didática sobre a temática água.

\section{Metodologia}

Neste trabalho, buscou-se analisar os mapas conceituais elaborados pelos alunos de um $4^{\circ}$ ano do ensino fundamental de uma escola pública, tanto nas características estruturais (forma/estrutura) quanto nas semânticas (conteúdo), a fim de averiguar os conhecimentos científicos desenvolvidos e a compreensão da técnica de construção de mapas conceituais.

A análise dos mapas se refere ao plano de aula 6 de uma sequência didática denominada: "Água: de onde vem, para onde vai?", que faz parte de uma pesquisa de mestrado. No Quadro 2, tem-se um parâmetro dos conteúdos trabalhados nessa sequência didática. 
Quadro 2 - Estrutura da sequência didática

\begin{tabular}{|c|c|c|c|}
\hline \multicolumn{4}{|c|}{ Sequência didática - Água: de onde vem, para onde vai? } \\
\hline $\begin{array}{l}\text { Plano de } \\
\text { aula }\end{array}$ & Conteúdos & Recursos didáticos & Objetivos de aprendizagem \\
\hline 1 e 2 & $\begin{array}{l}\text { A importância da presen- } \\
\text { ça da água no solo, no ar } \\
\text { e nos organismos vivos }\end{array}$ & $\begin{array}{l}\text { Imagens diversas com presença } \\
\text { ou não de: água; globo terrestre; } \\
\text { planta; cartaz; mapa conceitual. }\end{array}$ & $\begin{array}{l}\text { Perceber a presença da água em } \\
\text { todo o planeta: nos seres vivos, no } \\
\text { solo, no ar e nos organismos vivos. }\end{array}$ \\
\hline 3 e 4 & $\begin{array}{l}\text { Poluição e contaminação } \\
\text { da água em Araucária e } \\
\text { em outras cidades }\end{array}$ & $\begin{array}{l}\text { Roteiro do aluno para visita; ima- } \\
\text { gens diversas; quadro comparati- } \\
\text { vo; mapa conceitual. }\end{array}$ & $\begin{array}{l}\text { Perceber a ação do homem na po- } \\
\text { luição e contaminação da água e } \\
\text { suas consequências para a saúde. }\end{array}$ \\
\hline 5 e 6 & $\begin{array}{l}\text { Poluição e contaminação } \\
\text { da água em Araucária e } \\
\text { em outras cidades }\end{array}$ & $\begin{array}{l}\text { Texto: "Petrobrás é condenada } \\
\text { a pagar cerca de 1,4 bilhões por } \\
\text { derramar óleo nos Rios Barigui e } \\
\text { lguaçu"; imagens das indústrias } \\
\text { do Paraná; quadro de questões; } \\
\text { mapa conceitual. }\end{array}$ & $\begin{array}{l}\text { Identificar a poluição e contamina- } \\
\text { ção da água, em Araucária e em } \\
\text { outras cidades, e suas principais } \\
\text { fontes poluidoras. }\end{array}$ \\
\hline 7 e 8 & $\begin{array}{l}\text { Doenças causadas pela } \\
\text { falta de higiene e sanea- } \\
\text { mento básico }\end{array}$ & $\begin{array}{l}\text { Documentário sobre a poluição; } \\
\text { texto: "Nem tão pura assim"; fichas } \\
\text { sobre doenças causadas pela falta } \\
\text { de higiene e saneamento básico; } \\
\text { mapa conceitual. }\end{array}$ & $\begin{array}{l}\text { Perceber a ação do homem na po- } \\
\text { luição e contaminação da água e } \\
\text { suas consequências para a saúde. }\end{array}$ \\
\hline 9 e 10 & $\begin{array}{l}\text { Noções de saneamento } \\
\text { básico, estação de trata- } \\
\text { mento de água (ETA), po- } \\
\text { luição e contaminação da } \\
\text { água pelo ser humano }\end{array}$ & $\begin{array}{l}\text { Imagens; animação de compu- } \\
\text { tador; atividade impressa sobre } \\
\text { saneamento básico; mapa concei- } \\
\text { tual. }\end{array}$ & $\begin{array}{l}\text { Compreender o que é saneamen- } \\
\text { to básico e sua importância para a } \\
\text { saúde das pessoas. }\end{array}$ \\
\hline 11 e 12 & $\begin{array}{l}\text { Noções de saneamento } \\
\text { básico e estação de trata- } \\
\text { mento de esgoto (ETE) }\end{array}$ & $\begin{array}{l}\text { Imagens; textos impressos; vídeo } \\
\text { com animação; mapa conceitual. }\end{array}$ & $\begin{array}{l}\text { Compreender o que é saneamen- } \\
\text { to básico e sua importância para a } \\
\text { saúde das pessoas. }\end{array}$ \\
\hline
\end{tabular}

Fonte: elaboração dos autores.

Optou-se por fazer os mapas conceituais dos primeiros cinco planos de aula com o auxílio da professora, pois, supostamente, seria mais fácil de elaborar um mapa após os alunos já terem visto o assunto e construído um rol de conceitos, podendo, assim, representar o que aprenderam e a estrutura do pensamento sobre o conteúdo aprendido.

Na aula 6, organizados em grupos, entre dois e três alunos selecionados aleatoriamente pela professora, eles elaboraram um mapa conceitual sobre toda a sequência didática desenvolvida, demonstrando os conhecimentos científicos construídos bem como a compreensão da técnica de construção de mapas conceituais. Embora se tenha mapas de todos os seis planos de aula, centrou-se a análise somente do plano de aula 6. A escolha ficou centrada nessa etapa porque a atividade com o mapa conceitual foi feita sem a colaboração da professora, enquanto que os outros mapas fizeram parte da apropriação da técnica. 
Para a construção dos mapas conceituais, definiu-se que seriam avaliados quanto à sua estrutura e ao seu conteúdo. Com isso, pretendeu-se verificar se o mapa conceitual foi utilizado como uma ferramenta gráfica que permite organização, representação e compreensão de conhecimentos no ensino de ciências e auxilia na consolidação do conhecimento adquirido, tornando as informações mais acessíveis e claras.

Para analisar a estrutura dos mapas conceituais como estratégia diferenciada que contribui para a aprendizagem significativa, definiu-se que seriam utilizados os critérios de avaliação adaptados de Novak e Cañas (2010) - conceitos, proposições, hierarquia, ramificações, ligações cruzadas - e as contribuições de análise estrutural de Kinchin, Hay e Adams (2000 apud CORREIA; AGUIAR, 2017), identificados como: radial, linear e rede, que mostram o grau de compreensão do aluno sobre o conteúdo do mapa, ou seja, quanto maior o grau de interconexões entre as proposições, maior o conhecimento do aluno sobre o conteúdo mapeado. Pretendeu-se verificar a proficiência do mapeador na técnica, as características estruturais dos mapas e como os elementos apresentados se relacionam.

Segundo Aguiar e Correia, "somente os alunos que aprendem de forma significativa são capazes de produzir um MC em 'rede', enquanto que mapas 'lineares ou radiais' são persistentes durante o processo educativo dos alunos que optaram pela aprendizagem mecânica" (2013, p. 147).

Para analisar a semântica do mapa, isto é, o conteúdo dos mapas conceituais, pretendeu-se verificar a qualidade das relações estabelecidas, a clareza semântica e a expressão de significados traduzidas por elas por meio da diferenciação progressiva e da reconciliação integrativa, demonstrando o quanto houve de assimilação dos conhecimentos científicos.

Segundo Moreira e Buchweitz (1987), o mapa conceitual utilizado enquanto instrumento avaliativo concentra-se na obtenção de informações acerca da estrutura que o aluno vê para um conjunto de conceitos. Assim, importa determinar os conceitos apropriados e as relações estabelecidas entre eles, isto é, como o aluno estrutura, hierarquiza, diferencia, relaciona, discrimina e integra conceitos.

Em relação aos mapas conceituais:

[...] embora possam ser usados para dar uma visão geral do tema em estudo é preferível usá-los quando os alunos já têm certa familiaridade sobre o assunto, de modo que sejam potencialmente significativos e permitam a integração, reconciliação e diferenciação de significados dos conceitos (MOREIRA, 1997, p. 5).

Aguiar e Correia (2013) descrevem a importância de "atividades de treinamento" para o desenvolvimento de mapas conceituais. Para eles, "o sucesso na utilização dos MC como uma estratégia inovadora em sala de aula depende de um 
período de treinamento na técnica, que deve envolver professores (primeiro) e seus alunos (depois)" (2013, p. 156). As "atividades de treinamento" mencionadas pelos autores estão relacionadas à compreensão de domínio dos aspectos fundamentais de mapas conceituais, como relação entre conceitos, hierarquia conceitual, palavras de ligação e conexão semântica entre os conceitos.

Esses critérios têm o propósito de identificar as evidências de aprendizagem quanto à estrutura conceitual evidenciada pelos alunos, isto é, obter informações sobre o tipo de estrutura que o aluno vê para um dado conjunto de conceitos e como ele externaliza o seu conhecimento.

Embora o mapa conceitual não seja uma estratégia muito difícil de se aprender, de modo geral, os alunos têm dificuldade para construir sozinhos os primeiros. Assim, por ser algo novo e por estar em processo de adaptação, optou-se por analisar somente os mapas conceituais do plano de aula 6 , que finalizou o estudo sobre água e objetivou inserir noções de saneamento básico, como tratamento de água e esgoto, relacionando os aspectos envolvidos em tais processos, de modo que os alunos entendessem a sua importância para o reaproveitamento da água proveniente de rios e esgotos.

A elaboração do mapa conceitual foi referente à questão focal: o que nós aprendemos sobre a água? Esse mapa foi realizado em duplas ou trios, sem auxílio da professora, mas com a possibilidade de consulta. A atividade buscou verificar se a ferramenta utilizada auxiliou a aprendizagem mais significativa dos conceitos sobre a água nas aulas de ciências, visando à alfabetização científica.

Segundo Ausubel (2003 apud MOREIRA, 1997), o ser humano estrutura o conhecimento na memória de forma hierárquica, em termos de nível de abstração, generalidade e exclusividade de seus conteúdos. Essa organização é revelada durante a elaboração dos mapas, por meio da diferenciação progressiva e da reconciliação integrativa de conceitos, que são regularidades nos acontecimentos ou nos objetos, que se designam mediante algum termo, sendo a hierarquia usada para representar níveis cada vez mais detalhados de conceitos, facilitando, assim, o entendimento de um conteúdo.

\section{Analisando os mapas conceituais}

A seguir, apresentamos a análise dos oito mapas conceituais do plano de aula 6, que serão identificados como: MC1, MC2, MC3, MC4, MC5, MC6, MC7 e MC8. Esses mapas foram representados pelos pesquisadores utilizando a ferramenta CmapTools, mantendo a mesma estrutura e o mesmo conteúdo elaborados pelos alunos, e estão apresentados na Figura 1. 
Figura 1 - Compilação dos mapas conceituais do plano de aula 6
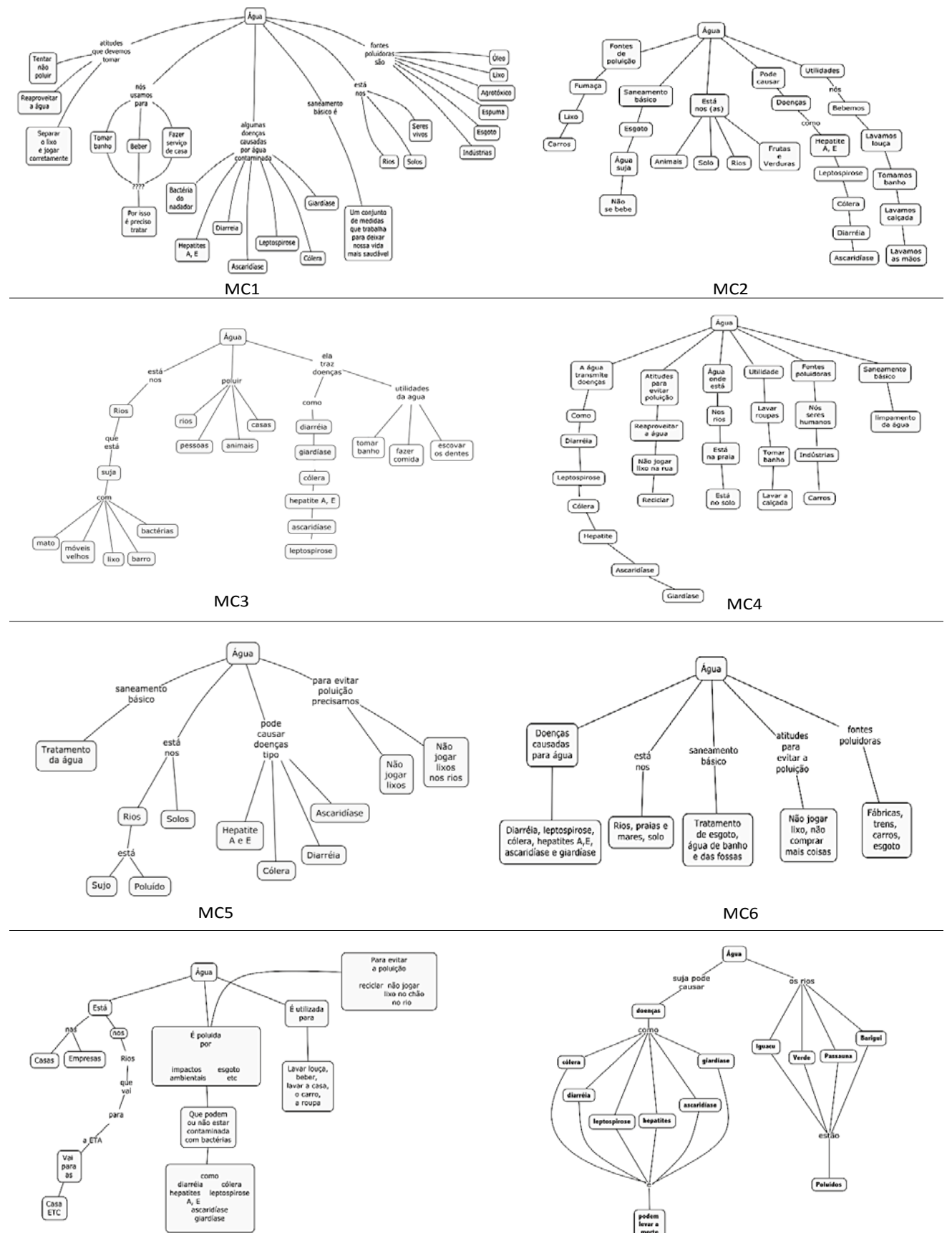

MC7

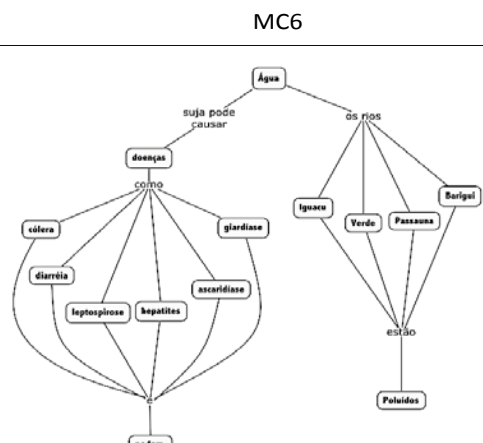

inter

MC8

Fonte: elaboração dos autores. 


\section{Conceitos}

Foram analisadas a quantidade e a validade (qualidade) dos conceitos apresentados nos mapas, isto é, se estão adequados ou não ao tema proposto.

O MC1 apresentou 25 conceitos adequados aos conteúdos da maioria das aulas, apesar de conter conceitos em forma de frases. O mapa conceitual apresentou os conceitos organizados predominantemente em forma radial, em que apresenta um conceito geral, a "água", e, em seguida, os conceitos subordinados: "tentar não poluir, reaproveitar a água, separar o lixo e jogar corretamente"; "tomar banho, beber, fazer o serviço de casa"; "bactéria do nadador, hepatites A e E, diarreia, ascaridíase, leptospirose, cólera, giardíase"; "um conjunto de medidas que trabalha para deixar nossa vida mais saudável"; "rios, solos, seres vivos, indústrias, esgoto, espuma, agrotóxico, lixo e óleo"; relacionando-os ao conceito geral. Um único conceito mais específico foi colocado abaixo dos subordinados: "por isso é preciso tratar", buscando relações entre o subordinado e o específico. Muitos conceitos estão parecidos com frases, e a dificuldade do aluno em escolher conceitos-chave relacionados ao tema para formular proposições demonstra que ainda não há familiaridade com a técnica de mapeamento conceitual.

O MC2 apresentou 27 conceitos adequados aos conteúdos da maioria das aulas, apesar de conter conceitos que cumprem a função de palavras de ligação. $O$ mapa conceitual apresentou os conceitos organizados em grande parte na forma linear, em que apresenta um conceito geral, a "água", e, em seguida, um encadeamento de conceitos subordinados: "fontes de poluição, fumaça, lixo e carros"; "saneamento básico, esgoto, água suja e não se bebe"; "está nos animais, solo e rios"; "pode causar doenças, hepatite A e E, leptospirose, cólera, diarreia e ascaridíase"; "utilidades, bebemos, lavamos louça, tomamos banho, lavamos calçada e lavamos as mãos".

O MC3 apresentou 21 conceitos adequados aos conteúdos da maioria das aulas. O mapa conceitual apresentou os conceitos organizados em forma predominantemente radial, em que apresenta um conceito geral, a "água", e, em seguida, os conceitos subordinados: "rios, suja, mato, móveis velhos, lixo, barro e bactérias"; "rios, pessoas, animais e casas"; "diarreia, giardíase, cólera, hepatite A, E, ascaridíase e leptospirose"; "tomar banho, fazer comida e escovar os dentes". Um único conceito mais específico foi colocado abaixo dos subordinados: "com mato, móveis velhos, lixo, barro e bactérias", buscando relações entre o subordinado e o específico.

O MC4 apresentou 27 conceitos adequados aos conteúdos da maioria das aulas, apesar de conter conceitos que cumprem a função de palavras de ligação. O mapa conceitual apresentou os conceitos organizados predominantemente na 
forma linear, em que apresenta um conceito geral, a "água", e, em seguida, um encadeamento de conceitos subordinados: "a água transmite doenças, como diarreia, leptospirose, cólera, hepatite, ascaridíase e giardíase"; "atitudes para evitar poluição, reaproveitar a água, não jogar lixo na rua e reciclar"; "água onde está, nos rios, está na praia, está no solo"; "utilidade, lavar roupas, tomar banho, lavar a calçada"; "fontes poluidoras, nos seres humanos, indústrias e carros"; "saneamento básico e limpamento da água"; relacionando-os ao conceito geral.

O MC5 apresentou 12 conceitos adequados aos conteúdos da maioria das aulas, apesar de conter conceitos em forma de frases. O mapa conceitual apresentou os conceitos organizados predominantemente na forma radial, em que apresenta um conceito geral, a "água", e, em seguida, os conceitos subordinados: "tratamento da água"; "rios, solo"; "hepatites A e E, cólera, diarreia, ascaridíase"; "não jogar lixos"; "não jogar lixos nos rios". Os únicos conceitos mais específicos foram colocados abaixo dos subordinados: "sujo e poluído", buscando relações entre o subordinado e o específico.

O MC6 apresentou 7 conceitos adequados aos conteúdos da maioria das aulas, apesar de conter todos os conceitos em forma de frases. Geralmente, isso ocorre quando o aluno não entende um determinado conceito ou não tem clareza de sua conexão com os outros conceitos. O mapa conceitual apresentou os conceitos organizados em forma radial, em que apresenta um conceito geral, a "água", e, em seguida, os subordinados: "diarreia, leptospirose, cólera, hepatites A e E, ascaridíase e giardíase"; "rios, praias e mares, solo"; "tratamento de esgoto, água de banho e da fossa"; "não jogar lixo, não comprar mais coisas"; "fábricas, trens, carros e esgoto"; relacionando-os ao conceito geral.

O MC7 apresentou 25 conceitos adequados aos conteúdos da maioria das aulas, apesar de conter conceitos em forma de frases ou como palavra de ligação ou, ainda, proposições dentro das "caixas". O mapa conceitual apresentou os conceitos organizados predominantemente na forma linear, em que apresenta um conceito geral, a "água", e, em seguida, os conceitos subordinados: "casas e empresas", e depois um encadeamento de conceitos: "nos, vai para as, casa, etc."; "é poluída por impactos ambientais e esgoto, etc. que podem ou não estar contaminada com bactérias, como a diarreia, cólera, hepatites A e E, leptospirose, ascaridíase e giardíase"; "é utilizada para lavar louça, beber, lavar a casa, o carro e a roupa"; "para evitar a poluição, reciclar, não jogar lixo no chão, no rio”.

O MC8 apresentou 14 conceitos adequados aos conteúdos da maioria das aulas. O mapa conceitual apresentou os conceitos organizados em forma de rede, em que apresenta um conceito geral, a "água", e, em seguida, os conceitos subordinados: "doenças, como cólera, diarreia, leptospirose, hepatites, ascaridíase e giardíase"; 
"Iguaçu, Verde, Passauna e Barigui”. Os conceitos mais específicos foram colocados abaixo dos subordinados: "podem levar a morte" e "poluídos", buscando relações entre o subordinado e o específico. Esse mapa foi o único que apresentou conceitos relacionados a um texto complementar apresentado em sala de aula.

A análise dos dados dos oito mapas permitiu identificar uma média de vinte conceitos. Importante observar que o conceito água foi o mais citado na condição de mais inclusivo ou geral, pois ele foi sugerido pela professora aos alunos. Para os conceitos intermediários, destacaram-se: i) doenças causadas pela contaminação da água (sete citações); ii) onde encontramos água (sete citações); iii) fontes de poluição (seis citações); iv) como evitar a poluição da água, a utilidade da água, saneamento básico (cinco citações cada um); v) como está a água dos rios (duas citações). Para os conceitos mais específicos, foram apresentados três: 1) doenças causadas pela contaminação da água; 2) saneamento básico; e 3) como está a água do rio.

Pode-se perceber que os conceitos ainda não estão bem integrados e são pouco hierarquizados, demonstrando pouca compreensão de conhecimento sobre o assunto e da forma de estruturação do mapa. Os alunos tentaram estabelecer uma hierarquia lógica entre os conceitos que aprenderam, relacionando o conceito geral de "água" a conceitos subordinados, mas o grande número de conceitos-chave em forma de frases ou agrupamento de palavras, sem uma diferenciação hierárquica relevante, mas que obedece a uma estrutura de conhecimento mais arbitrária, demonstrou uma aprendizagem mais próxima da mecânica.

\section{Proposições}

Analisou-se a clareza semântica das proposições, se foram rotuladas adequadamente e se estavam adequadas ao tema, ou seja, ao conteúdo trabalhado.

O MC1 apresentou seis proposições, isto é, inter-relações entre conceitos com as correspondentes palavras de ligação, e que conferem sentido lógico às proposições. Dessas proposições, quatro foram rotuladas adequadamente, duas rotuladas de forma não adequada e uma ligação entre conceitos não foi rotulada. A falta do termo de ligação impede o entendimento da relação conceitual, pois produz uma mensagem incompleta e se limita a representar a associação entre conceitos, e não uma relação conceitual com precisão. Nesse caso, não prejudicou a clareza semântica porque o conceito estava no formato de frase, o que não é o ideal.

Para a proposição rotulada adequadamente, os alunos expressaram que: "A água está nos rios, solos e seres vivos"; já na proposição não adequada: "Água atitudes devemos tomar, tentar não poluir, reaproveitar a água, separar o lixo e jogar 
corretamente"; para a proposição não rotulada: “Água nós usamos, tomar banho, beber, fazer serviço da casa, por isso é preciso tratar".

O MC2 não apresentou proposições, somente um encadeamento de ideias. Como no MC1, a falta do termo de ligação impede o entendimento da relação conceitual, comprometendo o entendimento do mapa.

O MC3 apresentou seis proposições. Dessas proposições, três foram rotuladas adequadamente e três rotuladas de forma não adequada, um termo de ligação mal selecionado pelo aluno pode prejudicar o entendimento do mapa. Para a proposição rotulada adequadamente, os alunos expressaram que: “A água está nos rios, solos e seres vivos"; já na proposição não adequada: “Água ela traz doenças, utilidades da água tomar banho, fazer comida e escovar os dentes".

O MC4 não apresentou proposições, somente um encadeamento de ideias. Assim como no MC2, a falta do termo de ligação dificulta o entendimento da relação conceitual, e isso pode ser devido à falta de compreensão sobre como se faz um mapa conceitual, pois o sequenciamento de ideias foi feito de maneira lógica. Pode-se ver no exemplo a seguir: “Água, saneamento básico, limpamento da água”; entretanto, se o termo de ligação tivesse sido colocado adequadamente, a proposição seria rotulada adequadamente: “Água passa por saneamento básico para que seja feita a sua limpeza".

O MC5 apresentou cinco proposições. Dessas proposições, quatro foram rotuladas adequadamente e uma rotulada de forma não adequada. Para a proposição rotulada adequadamente, os alunos expressaram que: "A água está nos rios e nos solos"; já na proposição não adequada: "Água, saneamento básico, tratamento de água”.

O MC6 apresentou quatro proposições. Dessas proposições, três foram rotuladas adequadamente, uma rotulada de forma não adequada e uma ligação entre conceitos não foi rotulada. Para a proposição rotulada adequadamente, os alunos expressaram que: “Água está nos rios, praias e mares, solo”; já na proposição não adequada: “Água saneamento básico, tratamento de esgoto, água de banho e das fossas"; para a proposição não rotulada: "Água, doenças causadas para a água, diarreia, leptospirose, cólera, hepatites A e E, ascaridíase e giardíase”.

O MC7 não apresentou proposições, mas somente um encadeamento de ideias. Houve uma tentativa de proposição na inter-relação de conceitos: “Água está nas casas e nas empresas"; porém, a palavra que faz a ligação não foi colocada corretamente. As outras tentativas de ligação entre conceitos não estão sem lógica, mas também não estão de acordo com os parâmetros de um mapa conceitual.

O MC8 apresentou seis proposições. Dessas proposições, cinco foram rotuladas adequadamente e uma rotulada de forma não adequada. Para a proposição rotulada adequadamente, os alunos expressaram que: “Água suja pode causar doenças 
como cólera, diarreia, leptospirose, hepatites, ascaridíase e giardíase e podem levar a morte"; já na proposição não adequada: "Água os rios Iguaçu, Verde, Passauna, Barigui".

A análise dos oito mapas permitiu identificar que seis mapas tiveram proposições válidas, isto é, tiveram interconexões rotuladas adequadamente ou não. Os outros dois casos não puderam ser classificados como mapas por não serem rotulados, ou seja, não apresentaram a palavra de ligação entre conceitos. Quanto maior o grau de interconexões entre as proposições, maior o conhecimento do aluno sobre o conteúdo mapeado. Pode-se observar que os alunos tiveram dificuldade em estruturar os seus mapas.

A clareza semântica fica comprometida pela ausência de um bom termo de ligação, pois não é possível identificar a relação entre os conceitos. Um fator que pode contribuir para a ocorrência de proposições desse tipo é a compreensão limitada sobre o tema em discussão ou sobre como construir bons mapas conceituais.

A análise também permitiu identificar um mínimo de quatro e um máximo de seis proposições rotuladas. As proposições que se destacaram foram: i) doenças causadas pela contaminação da água são diarreia, cólera, hepatites A e E, leptospirose, ascaridíase e giardíase; ii) encontramos água em solo, mares e seres vivos; iii) as fontes de poluição da água são os seres humanos, as indústrias, a água de banho, as fossas e os carros.

\section{Hierarquia}

Foram analisadas as estruturas hierárquicas dos oito mapas, a fim de verificar se representavam níveis cada vez mais detalhados de conceitos, além de verificar a quantidade de níveis apresentados. O grau de hierarquização presente em um mapa conceitual pode ser tomado como indício da diferenciação progressiva ou da reconciliação integrativa ao ser estruturado pelos alunos.

Nos oito mapas conceituais, há níveis de hierarquia ou tentativas, variando entre dois e três nas estruturas consideradas válidas. Somente quatro mapas demonstraram uma sequência que vai de conceitos mais inclusivos até os menos inclusivos e passa pelos intermediários, considerando o contexto do tema trabalhado na sequência didática durante as aulas de ciências.

MC1, MC3, MC5 e MC8 apresentam três níveis de hierarquia, entretanto, somente o MC8 possui uma estrutura de mapa em forma de rede e melhor estruturado. Os demais mapas têm a predominância de uma estrutura radial. O MC6 apresenta um nível hierárquico somente e possui uma estrutura exclusivamente radial. 
Somente alunos que aprendem um tema de forma significativa são capazes de produzir mapas em rede, enquanto que mapas radiais e lineares são produzidos por alunos que optaram pela aprendizagem mecânica. A complexidade do mapa pode ser verificada pelo número de níveis hierárquicos presentes nessas estruturas, em que uma estrutura radial tem somente dois níveis hierárquicos, enquanto as demais possuem vários. É normal dar-se "prioridade ao ordenamento hierárquico vertical [...], sendo o eixo horizontal interpretado como menos estruturado, enquanto que o vertical reflete bem o grau de inclusividade de conceitos" (MOREIRA; BUCHWEITZ, 1987, p. 28).

Os mapas MC2, MC4 e MC7 possuem uma estrutura linear, apresentando um encadeamento sequencial dos conceitos. Nesse caso, o entendimento que o aluno possui sobre o tema é suficiente para criar relações conceituais sem abusar do uso exclusivo do conceito inicial.

\section{Ramificações}

Os mapas MC1 e MC4 possuem seis ramificações cada, mas somente no MC1 elas são válidas. MC2 e MC6 possuem cinco ramificações cada, porém, não são válidas. Os mapas MC3 e MC5 possuem quatro ramificações cada, mas somente no MC3 elas são válidas. Os mapas M7 e M8 possuem três e duas ramificações, respectivamente, mas somente no M8 elas são válidas.

A capacidade do aluno em escolher conceitos relacionados ao tema e dispô-los espacialmente no mapa conceitual para formular proposições já demonstra certa familiaridade com a técnica de mapeamento conceitual. Entretanto, na sua elaboração, a maioria dos alunos não conseguiu selecionar os conceitos-chave, e a formação de ramos e proposições se apresenta ainda pouco densa e articulada entre si.

\section{Ligações cruzadas}

Em relação ao critério cross links, nenhum dos oito mapas apresentou relações cruzadas, demonstrando pouca representatividade dos conteúdos abordados durante a sequência didática. Para Novak e Cañas (2010), as ligações cruzadas auxiliam na percepção do modo como um conceito, em um domínio de conhecimento representado no mapa, relaciona-se com outro conceito de domínio diferente, além disso, são importantes para mostrar quais as relações que o aluno compreende entre os subdomínios do mapa construído.

O estabelecimento de relações cruzadas entre os conceitos, muitas vezes, torna-se tarefa difícil para o aluno entender, principalmente para as crianças na faixa 
etária dos 8-9 anos, mas, à medida que elas se desenvolvem, vão construindo novos conceitos, cada vez mais complexos.

\section{Comparação das categorias analisadas nos mapas conceituais}

Para a análise comparativa dos mapas conceituais elaborados no plano de aula 6 , foram estabelecidos critérios de classificação no que se refere às categorias: conceitos, proposições, hierarquia, ramificações e ligações cruzadas. Os critérios de análise adotados têm base nos critérios utilizados por Novak (1998) e podem ser observados na Tabela 1 .

Tabela 1 - Análise comparativa dos mapas conceituais

\begin{tabular}{|c|c|c|c|c|c|c|c|c|c|c|}
\hline Categorias & $\begin{array}{l}\text { Elementos } \\
\text { observados }\end{array}$ & MC1 & MC2 & MC3 & MC4 & MC5 & MC6 & MC7 & MC8 & Média \\
\hline \multirow{6}{*}{$\begin{array}{l}\text { Conceitos } \\
\text { Regularidades ou } \\
\text { padrões percebidos } \\
\text { em eventos ou obje- } \\
\text { tos e pertinentes ao } \\
\text { conteúdo água }\end{array}$} & Adequados & 25 & 27 & 21 & 27 & 12 & 07 & 25 & 14 & 20 \\
\hline & Inadequados & - & - & - & - & - & - & - & - & - \\
\hline & $\begin{array}{l}\text { Total de conceitos } \\
\text { no mapa }\end{array}$ & 25 & 27 & 21 & 27 & 12 & 07 & 25 & 14 & 20 \\
\hline & Conceito geral & 1 & 1 & 1 & 1 & 1 & 1 & 1 & 1 & 1 \\
\hline & $\begin{array}{l}\text { Conceito } \\
\text { subordinado/ } \\
\text { intermediário }\end{array}$ & 23 & - & 19 & 26 & - & - & - & - & 8,5 \\
\hline & $\begin{array}{l}\text { Conceito } \\
\text { específico }\end{array}$ & 1 & - & 1 & - & 1 & - & - & - & 0,38 \\
\hline \multirow{4}{*}{$\begin{array}{l}\text { Proposições } \\
\text { Relacionam-se os } \\
\text { conceitos válidos em } \\
\text { níveis hierárquicos } \\
\text { adequados }\end{array}$} & $\begin{array}{l}\text { Quantidade } \\
\text { de proposições }\end{array}$ & 6 & - & 6 & - & 5 & 4 & - & 6 & 3 \\
\hline & $\begin{array}{l}\text { Rotuladas e } \\
\text { adequadas }\end{array}$ & 4 & - & 3 & - & 4 & 3 & - & 5 & 2 \\
\hline & $\begin{array}{l}\text { Rotuladas e não } \\
\text { adequadas }\end{array}$ & 1 & - & 3 & - & 1 & 1 & - & 1 & 1 \\
\hline & Não rotuladas & 1 & 5 & - & 6 & - & 1 & 5 & - & 2 \\
\hline $\begin{array}{l}\text { Hierarquia } \\
\text { Parte de conceito mais } \\
\text { geral para conceitos } \\
\text { menos abrangentes }\end{array}$ & Número de níveis & 3 & - & 3 & - & 3 & 1 & - & 3 & 1,6 \\
\hline Ramificações & Número de ramos & 6 & 5 & 4 & 6 & 4 & 5 & 3 & 2 & 4,4 \\
\hline \multirow{2}{*}{$\begin{array}{l}\text { Cross links } \\
\text { Inter-relaciona concei- } \\
\text { tos de forma adequada }\end{array}$} & Sim & - & - & - & - & - & - & - & - & - \\
\hline & Não & - & - & - & - & - & - & - & - & - \\
\hline
\end{tabular}

Fonte: elaboração dos autores.

Os oito mapas conceituais apresentaram conceitos adequados ao conteúdo trabalhado - água -, apesar de alguns alunos apresentarem dificuldade em identificar 
os conceitos-chave para compor o mapa. Como exemplo, pode-se destacar o MC1, sendo um dos conceitos formado por uma frase: "um conjunto de medidas que trabalha para deixar nossa vida mais saudável".

Pode-se notar, também, que o número de conceitos subordinados varia entre dois e três níveis de hierarquia. Possivelmente, isso ocorreu devido à natureza da questão focal e à sua abrangência, pois o mapa envolvia todo o conteúdo estudado sobre a água. $\mathrm{O}$ mesmo motivo também se refere à categoria das ramificações, pois esses mapas têm mais conteúdo a ser representado, e não necessariamente pela evidência de que o ensino foi potenciamente bem-sucedido e significativo.

O que corrobora com essa hipótese é que os conceitos mais específicos em níveis maiores de hierarquia praticamente não aparecem, mas, quando aparecem, são pouco significativos. Assim, pode-se inferir que os alunos se limitaram a representar os conceitos mais gerais e que tiveram dificuldade para identificar os conceitos mais específicos, dessa forma, o volume de informações nos mapas somente representa a quantidade de conteúdo e não a sua especificidade (profundidade).

A análise das proposições ou inter-relações entre conceitos evidenciou que, em metade dos mapas, elas não apareceram rotuladas, como no exemplo: "água, utilidade, lavar louça, tomar banho, lavar a calçada".

A maioria das proposições que foram rotuladas de forma adequada atribuiram algum significado lógico e permitiram certa clareza semântica, ou seja, uma mensagem compreensível. Houve menos proposições rotuladas e não adequadas do que proposições não rotuladas. Proposições rotuladas e não adequadas são aquelas em que dois ou mais termos conceituais, unidos por um termo de ligação, não apresentam significado totalmente lógico. Nesses mapas, as palavras selecionadas para inter-relacionar conceitos se mostraram confusas e não conseguiram atribuir significado para o processo de organização do conhecimento.

$\mathrm{Na}$ análise, pôde-se contabilizar um maior número de mapas com estrutura radial, seguida da linear e um único com estrutura em rede. Os mapas com estrutura radial, linear e em rede mostram o grau de compreensão do aluno sobre o conteúdo do mapa, quanto maior o grau de interconexões entre as proposições, maior o conhecimento do aluno sobre o conteúdo mapeado, que é representado pela diferenciação progressiva e reconciliação integrativa. Como descrito por Aguiar e Correia (2013), alunos que produzem mapas com estrutura em rede demonstram uma aprendizagem de forma significativa, já aqueles que produzem estruturas lineares ou radiais demonstram uma aprendizagem mais mecânica.

Como exemplo de um bom mapa (Figura 2), com uma estrutura em rede, com uma relação entre conceitos que expressa diferenciação progressiva, pode-se citar o MC8, que apresenta conceitos representativos do conteúdo trabalhado nas aulas, 
pelo menos três níveis de hierarquia e proposições com certa clareza semântica. Esse mapa está longe de ser um mapa ideal, mas, devido à inexperiência, à falta de tempo e a outros fatores, não se pode tirar o mérito da tentativa.

Figura 2 - Mapa conceitual considerado bom*

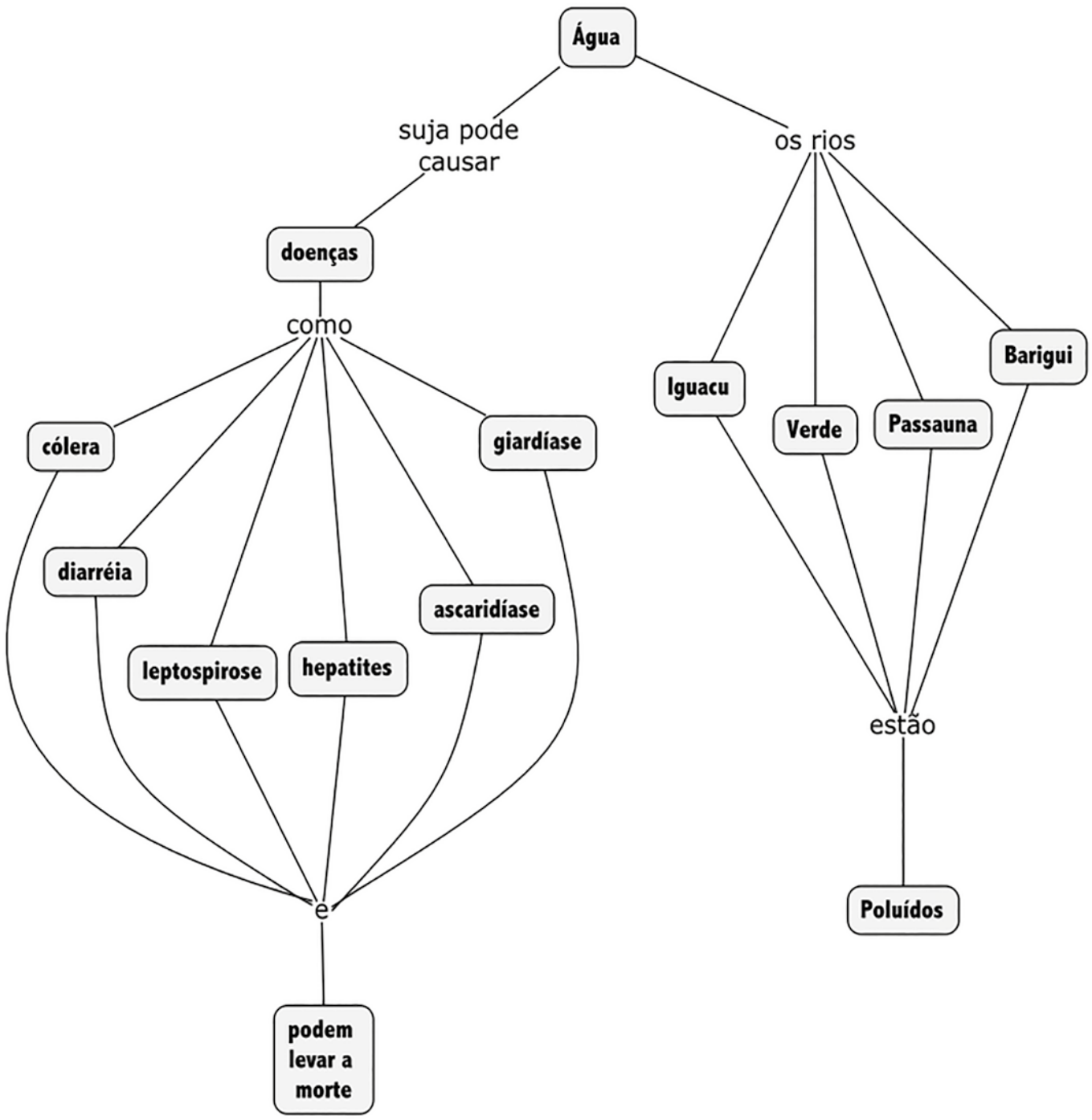

Fonte: elaboração dos autores.

* No mapa conceitual, foi mantida a grafia original da elaboração dos alunos. 
Um exemplo de mapa que não atende aos critérios de referencia é o MC7 (Figura 3), que, além de evidenciar a falta de proficiência na técnica de mapaeamento conceitual, também mostra a dificuldade com a organização de ideias e sua representação.

Figura 3 - Mapa conceitual considerado ruim

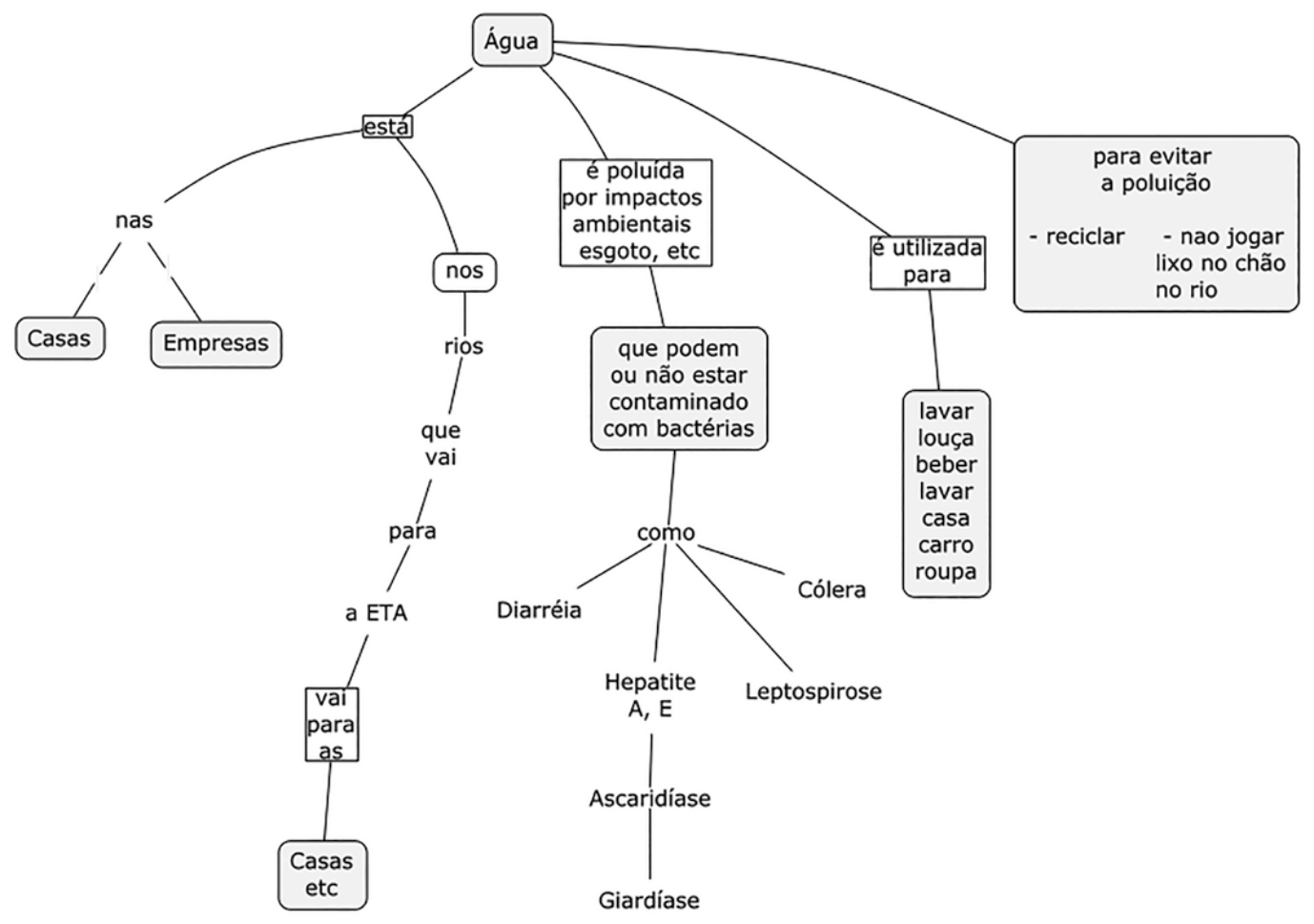

Fonte: elaboração dos autores.

Segundo Moreira (1997), no mapa conceitual, o aprendiz expressa sua organização mental sobre um determinado campo de conhecimento, por meio de um esquema visual que possibilita representar as relações que ele realiza entre os conceitos.

Sabe-se que não existe um mapa conceitual "correto" sobre determinado conteúdo, o que é importante não é se esse mapa está certo ou não, mas, sim, se ele dá evidências de que o aluno esteja aprendendo significativamente o conteúdo, ao invés de se preocupar em atribuir um escore ao mapa. Ausubel "não proporcionou instrumentos simples e funcionais para ajudar os professores a averiguar 'o que 
o aluno sabe" (NOVAK; GOWIN, 1996, p. 56), para isso, existem os instrumentos educativos - mapas conceituais. Eles foram "desenvolvidos especificamente para estabelecer comunicação com a estrutura cognitiva do aluno e para externalizar o que este já sabe de forma a que tanto ele como o professor se apercebam disso" (NOVAK; GOWIN, 1996, p. 56).

Dessa forma, seria importante que, após a construção do mapa conceitual, a professora realizasse uma revisão e uma reflexão sobre sua construção. Além de analisar o número de links válidos e o grau de relação existente entre cada um, as proposições entre conceitos, a quantidade de ramificações, a estrutura hierárquica, também é útil identificar as ideias errôneas presentes nas ligações incorretas que formam proposições inválidas dos indicadores e a inclusão de conceitos que não estão relacionados com o conceito principal.

Analisar somente para as proposições e os links válidos pode impedir uma visão mais ampla sobre a estrutura geral de como se está estruturando o conhecimento. Ao se considerar também o que não está "correto", pode-se ter noção do processo que o aluno está utilizando para compreender determinado conceito. Como destaca Tavares, "[...] não existe um mapa certo ou mapa errado. Existem mapas com uma demonstração de grande conhecimento sobre as possíveis relações entre os conceitos mostrados" (2007, p. 78).

Souza e Boruchovitch (2010) afirmam que os erros servem de ponte para a aprendizagem, desde que sejam identificados e trabalhados, visando a uma evolução. Os erros são instrumentos que servem para "identificar as dificuldades de aprendizagem, orientando para aspectos a serem superados; favorecer a reelaboração de conceitos e sua consequente sedimentação, integração e ampliação dos conhecimentos" (2010, p. 182). Assim, um mapa conceitual revela aquilo que o aluno sabe e, também, o que ainda não conhece suficientemente sobre um determinado conceito para construí-lo de forma significativa.

Segundo Toulmin (2001), conceitos são a essência da compreensão humana. Já, para Moreira, "com conceitos vamos muito além de apontar regularidades em eventos ou objetos: construímos e damos significado a proposições" (2013, p. 10). Conforme são construídos novos conceitos e relações, o conhecimento vai ficando mais elaborado, mais diferenciado e capaz de atuar como subsunçor para outros novos conhecimentos.

Além disso, é importante destacar que os alunos iniciaram a participação na pesquisa sem nenhum conhecimento da ferramenta mapas conceituais, eles foram adquirindo a habilidade ao longo das aulas. Considerando-se os resultados apresentados, a importância e as possibilidades de crescimento dessa área de estudo, sugere-se que as pesquisas e discussões sobre mapas conceituais na educação bá- 
sica sejam incorporadas nos cursos de formação inicial e continuada de professores que atuam principalmente no ensino fundamental. Os mapas conceituais podem ser utilizados com o intuito de implementar ações educativas para tornar mais significativa a aprendizagem dos alunos, permitindo assim possíveis contribuições relevantes para o processo de ensino-aprendizagem.

\section{Considerações finais}

O mapa conceitual não é uma simples reprodução do conhecimento, ele exige que o aprendiz reflita sobre um determinado conteúdo para poder representá-lo na forma de conceitos e criar hierarquizações e conexões que retratem a estrutura cognitiva de quem o elabora. Para elaborar um mapa conceitual hierárquico, o aluno deve refletir sobre quais são os conceitos mais inclusivos e quais os menos inclusivos. Assim, ao representar o seu conhecimento, tanto o aluno como o professor podem verificar se ocorreu realmente a reorganização cognitiva, isto é, a aprendizagem significativa.

É muito importante que aluno e professor tenham um mínimo de conhecimento da técnica de mapeamento, pois se percebeu que leva tempo para que o sujeito se familiarize com ela, e, certamente, os resultados podem ser mais satisfatórios ao se observar essa orientação. Aguiar e Correia descrevem a importância de "atividades de treinamento" para o desenvolvimento de mapas conceituais: "o sucesso na utilização dos MC como uma estratégia inovadora em sala de aula depende de um período de treinamento na técnica" (2013, p. 156). Mais pontualmente, é imprescindível que o professor, além de saber fazer um mapa conceitual, tenha conhecimento de seu embasamento teórico, assim como dos seus variados usos, e saiba que sua participação precisa ser mais efetiva como mediador e avaliador em todo o processo.

Sugere-se que essa técnica seja desenvolvida em pequenos grupos e, também, sempre que necessário, individualmente. Aconselha-se que seja um trabalho desenvolvido em longo prazo, para que haja tempo de adaptação à técnica e para que os sujeitos envolvidos usufruam desse recurso.

Como constatado na pesquisa realizada por Silva e Lorenzetti (2016), os trabalhos sobre mapas conceituais estão mais voltados para o ensino superior, para o ensino médio e para o ensino fundamental II do que para os anos iniciais do ensino fundamental. Além disso, o mapa conceitual é utilizado como recurso para aquisição de aprendizagem significativa ou como uma estratégia na formação continuada de professores, para avaliação ou planejamento. 
Pode-se concluir que o mapa conceitual é um recurso didático eficiente de trabalho, porém, há necessidade de um efetivo conhecimento dos elementos constituintes de um mapa, da importância do "treinamento" para poder construir mapas cada vez mais bem estruturados e complexos. Assim, para o professor comprometido com o processo, tanto no que diz respeito à apresentação da ferramenta de trabalho (mapas) quanto ao seu papel mediador, conhecer a teoria que embasa 0 recurso torna-se fundamental para o progresso de qualquer metodologia implantada em sua prática na sala de aula.

É possível que o desconhecimento da técnica de utilização de mapas conceituais como prática pedagógica e o despreparo dos profissionais sejam os motivos do desinteresse dos professores, principalmente nos anos iniciais. A técnica exige tempo e esforço para se efetivar, os professores necessitariam mudar o seu fazer pedagógico, precisariam elaborar metodologias de trabalho com atividades diferenciadas e com mapas, a fim de estimular os alunos e, assim, promover a aprendizagem significativa.

O mapa conceitual como recurso didático é um instrumento potencialmente significativo no ensino de ciências naturais, podendo ser adaptado para qualquer área do conhecimento, desde que haja interesse dos docentes em inovar nas suas aulas.

Considerando que o objetivo era averiguar os conhecimentos científicos desenvolvidos, bem como a compreensão da técnica de construção e mapas conceituais, verificou-se, por meio das análises dos mapas conceituais produzidos pelos alunos, que a utilização da ferramenta didática contribuiu de certa forma para a organização, a representação, a sistematização e a compreensão do conhecimento, tornando as informações mais acessíveis e claras.

Alternativas de ensino diferenciadas, como o mapa conceitual, que é uma estratégia pedagógica utilizada no ensino para a construção de conhecimentos científicos pelos alunos, podem ajudar os estudantes a integrar e relacionar informações, conferindo significado ao que estão estudando.

É possível, durante a elaboração de um mapa conceitual, desenvolver novas relações conceituais e dar significado a conceitos, além de externalizar e obter o conhecimento conceitual, tanto nos mapas corretos como nos errôneos, identificando as ideias prévias dos alunos. O mapa conceitual possibilita, também, a mudança do ponto de vista sobre a validade de uma proposição (NOVAK, 1998), sendo uma poderosa ferramenta de avaliação, pois possibilita obter o grau de organização hierárquica, a diferenciação progressiva e a reconciliação integrativa que os alunos apresentam. 
Com relação à análise dos mapas conceituais elaborados pelos alunos, a fim de verificar como o conhecimento foi representado e a compreensão da técnica de mapeamento, destaca-se que houve ampliação do vocabulário científico proposto no plano de aula, porém, sem profundidade nas relações entre conceitos, e nem todos demonstraram compreensão plena daquilo que representaram. Assim, constatou-se que os alunos tiveram dificuldade para representar o conhecimento por intermédio dos mapas, não porque não sabiam, mas pela inexperiência na sua construção e utilização. De modo geral, a elaboração dos mapas melhorou progressivamente durante o processo de intervenção, mas ficou longe de ser o ideal.

A construção dos mapas, coletivamente ou de forma individual, requer atenção e dedicação especial por parte do professor quanto à assistência dispensada, é preciso um período considerável de tempo para a aplicação e as intervenções.

Para que se concretizem tais ações pedagógicas nas escolas, é preciso introduzir e/ou ampliar o conhecimento sobre mapas conceituais nos cursos de Pedagogia, Biologia, entre outros, e oferecer cursos de formação continuada para os professores, a fim de ampliar o conhecimento acerca da técnica de mapeamento. Esta pesquisa concluiu que os estudos com mapas conceituais no ensino fundamental, apesar de crescentes, ainda são incipientes.

\section{Referências}

AGUIAR, J. G.; CORREIA, P. R. M. Como fazer bons mapas conceituais: estabelecendo parâmetros de referências e propondo atividades de treinamento. Revista Brasileira de Pesquisa em Educação em Ciências, Belo Horizonte, v. 13, n. 2, p. 141-157, 2013. Disponível em: <https://seer. ufmg.br/index.php/rbpec/article/view/2469>. Acesso em: 15 out. 2017.

AUSUBEL, D. P. Aquisição, retenção de conhecimentos: uma perspectiva cognitiva. Lisboa: Plátano, 2003.

CAÑAS, A. J., NOVAK, J. D.; REISKA, P. How good is my concept map? Am I a good Cmapper? Knowledge Management \& E-Learning, Hong Kong, v. 7, n. 1, p. 6-19, 2015.

CORREIA, P. R. M.; AGUIAR, J. G. Avaliação da proficiência em mapeamento conceitual a partir da análise estrutural da rede proposicional. Ciência \& Educação, Bauru, jan./mar. 2017. Disponível em: <http://www.redalyc.org:9081/home.oa?cid=1523344>. Acesso em: 15 out. 2017.

MOREIRA, M. A.; BUCHWEITZ, B. Mapas conceituais: instrumentos didáticos de avaliação e analise de curriculo. Sao Paulo: Moraes, 1987.

MOREIRA, M. A. Mapas conceituais e aprendizagem significativa. 1997. Disponível em: <https:// www.if.ufrgs.br/ moreira/mapasport.pdf>. Acesso em: 22 ago. 2017.

Aprendizagem significativa em mapas conceituais. 2013. Disponível em: <https:// pt.scribd.com/document/337705771/Aprendizagem-Significativa-por-meio-de-Mapas-Conceituais-pdf $>$. Acesso em: 22 ago. 2017. 
NOVAK, J. D. Learning, creating, and using knowledge: concept maps as facilitative tools for schools and corporations. Mahwah, N. J.: Lawrence Erlbaum \& Assoc., 1998.

NOVAK, J. D.; CANÃS, A. J. A teoria subjacente aos mapas conceituais e como elaborá-los e usálos. 2010. Disponível em: <http://cmap.ihmc.us/Publications/ResearchPapers/TeoriaSubjacenteAosMapasConceituais.pdf>. Acesso em: 1ํㅡㄴ 2016.

NOVAK, J. D.; GOWIN, D. B. Aprender a aprender. Lisboa: Plátano, 1996. v. 2.

SILVA, V. R. da; LORENZETTI, L. As contribuições dos mapas conceituais para a educação em ciências nos anos iniciais: uma análise dos trabalhos apresentados nos Enpecs. In: SIMPÓSIO NACIONAL DE ENSINO DE CIÊNCIA E TECNOLOGIA, 5. Anais... Curitiba, 2016. Disponível em: <http://www.pg.utfpr.edu.br/sinect/anais/artigos/>. Acesso em: 22 ago. 2017.

SOUZA, N. A; BORUCHOVITCH, E. Mapa conceitual: seu potencial como instrumento avaliativo. Pro-Posições, Campinas, v. 21, n. 3, p. 173-192, 2010. Disponível em: <http://www.scielo. br/scielo.php?pid=S0103-73072010000300011 \&script=sciabstract\&tlng=pt $>$. Acesso em: 22 ago. 2017.

TAVARES, R. Construindo mapas conceituais. Ciência \& Cognição, Rio de Janeiro, v. 12, p. 72 85, 2007. Disponível em: <http://www.cienciasecognicao.org/pdf/v12/m347187.pdf>. Acesso em: 22 ago. 2017.

TOULMIN, S. Os usos do argumento. São Paulo: Martins Fontes, 2001. 